\begin{tabular}{|c|c|}
\hline Title & Sr substitution effects on atomic and local electronic structure of $\mathrm{C} a 2 \mathrm{~A} I \mathrm{MnO} 5+\delta$ \\
\hline Author(s) & Kunisada, Y uji; Saito, Genki; Hay ami, Kazuki; Nomura, Takahiro; Sakaguchi, Norihito \\
\hline Citation & $\begin{array}{l}\text { Surface and interface analy sis, 51(1), 65-69 } \\
\text { https://doi .org/10.1002/sia.6549 }\end{array}$ \\
\hline Issue Date & $2019-01$ \\
\hline Doc URL & http://hdl.handle.net/2115/76445 \\
\hline Rights & $\begin{array}{l}\text { This is the peer reviewed version of the following article: Kunisada Y, Saito G, Hay ami K, Nomura T, Sakaguchi N. Sr } \\
\text { substitution effects on atomic and local electronic structure of Ca2A IMnO } 5+\delta \text {. Surf Interface A nal. 2019;51:65-69. , } \\
\text { which has been published in final form at https://doi.org/10.1002/sia.6549. This article may be used for non-commercial } \\
\text { purposes in accordance with Wiley Terms and Conditions for U se of Self-A rchived Versions. }\end{array}$ \\
\hline Tyре & article (author version) \\
\hline File Information & Manuscript_SIA_SrAIMnO_accepted.pdf \\
\hline
\end{tabular}

Instructions for use 


\title{
Sr Substitution Effects on Atomic and Local Electronic Structure of $\mathrm{Ca}_{2} \mathrm{AlMnO}_{5+\delta}$
}

\author{
Yuji Kunisada*, Genki Saito, Kazuki Hayami, Takahiro Nomura, Norihito Sakaguchi \\ Center for Advanced Research of Energy and Materials, Faculty of Engineering, \\ Hokkaido University, Kita 13 Nishi 8, Kita-ku, Sapporo, Hokkaido 060-8628, Japan \\ E-mail: kunisada@eng.hokudai.ac.jp
}

\begin{abstract}
We performed the first-principles calculations based on spin-polarized density functional theory to investigate the $\mathrm{Sr}$ substitution effects on the atomic and local electronic structure of $\mathrm{Ca}_{2} \mathrm{AlMnO}_{5+\delta}$. The ionic radius of $\mathrm{Sr}^{2+}$ is larger than that of $\mathrm{Ca}^{2+}$, thus, the lattice expansion occurs with $\mathrm{Sr}$ substitution. From the total energy calculations, we found that $\mathrm{Sr}$ substitution makes the oxygen absorbed phase unstable and realizes the lower operation temperature. From the point of atomic structure, $\mathrm{Sr}$ substitution lengthens the bond length between $\mathrm{Mn}$ and $\mathrm{O}$ atoms connecting $\mathrm{Mn}$ and $\mathrm{Al}$ atoms in $\mathrm{Al}$ tetrahedral $\left(\mathrm{O}_{\mathrm{Mn}-\mathrm{Alt}}\right)$ in oxygen absorbed phase, because the large $\mathrm{Sr}^{2+}$ prevents the release of the Jahn-Teller distortion. We also found that the covalent bonding between $\mathrm{Mn}$ and $\mathrm{O}_{\mathrm{Mn} \text {-Alt }}$ atoms weaken with $\mathrm{Sr}$ substitution by the local electronic structure analysis, which results in the unstable oxygen absorbed phase and weak prepeak and main peak intensity near the onset of O-K edge ELNES of OMn-Alt atoms.
\end{abstract}

Keywords: Oxygen storage material, Density functional theory, brownmillerite oxide, Jahn-Teller distortion 


\section{Introduction}

Perovskite oxides $A B \mathrm{O}_{3}$ show the various unique properties, and therefore, can play important roles in many scientific and engineering fields, for instance, solar cells, oxygen storage materials(OSM), and so on. In the case of application for OSM, the reversible topotactic transformation between $A B \mathrm{O}_{3}$ and $A B \mathrm{O}_{3-\delta}$ occurs in the oxygen intake and release process. Recently, it has been reported that brownmillerite oxides, which are the vacancy-ordered perovskite oxides, show high oxygen storage capability and cycle prperties.[1-3] Especially, $\mathrm{Ca}_{2} \mathrm{AlMnO}_{5+\delta}$, which shows the ready availability of the constituent elements and $3 \mathrm{wt} . \%$ oxygen storage[3], is one of the promising OSM. In the topotactic transformation from $\mathrm{Ca}_{2} \mathrm{AlMnO}_{5}$ to $\mathrm{Ca}_{2} \mathrm{AlMnO}_{5.5}$, layer-by-layer transformation of $\mathrm{AlO}_{4}$ tetrahedra into $\mathrm{AlO}_{6}$ octahedra occurs. However, $\mathrm{Ca}_{2} \mathrm{AlMnO}_{5+\delta}$ shows the large temperature hysteresis between oxygen intake and release, and slow reaction rate.

It has also been reported that we can control the oxygen storage properties of $\mathrm{Ca}_{2} \mathrm{AlMnO}_{5+\delta}$, for instance, equilibrium temperature and oxygen partial pressure for the oxygen storage, through the substitution of constituent elements.[4] For further material design using heteroatomsubstitution, we have to understand the substitution effect on the atomic and local electronic structure. Because of its vacancy-ordered structure, brownmillerite oxide $\mathrm{Ca}_{2} \mathrm{AlMnO}_{5.5}$ contains complex chemical bonding, i.e. five non-equivalent oxygen sites. In the case of $\mathrm{Ca}_{2} \mathrm{AlMnO}_{5}$, three non-equivalent oxygen sites exist. Therefore, atomic-scale analysis is required. Recently, we reported the atomic and local electronic structures of $\mathrm{Ca}_{2} \mathrm{AlMnO}_{5+\delta}$ using the high-angle annular dark-field scanning transmission electron microscopy (HAADF-STEM) with electron energy-loss spectroscopy (EELS) and first-principles calculations based on spin-polarized density functional theory (DFT).[5] We found that the good agreements with the atom-resolved O-K edge electron energy-loss near-edge structure (ELNES) at each non-equivalent $\mathrm{O}$ atom column and corresponding density of states (DOS) of $p$ orbitals of corresponding non-equivalent $\mathrm{O}$ atoms. Therefore, theoretical atomic-scale analysis of the substitution effects using DFT can enhance the comprehension of the experimental analysis.

In this paper, we focused on the $\mathrm{Sr}$ substitution at $\mathrm{Ca}$ sites, i.e., $\mathrm{Sr}_{2} \mathrm{AlMnO}_{5+\delta}$, as shown in Fig. 1. We performed the first-principles electronic structure calculations based on spin-polarized DFT to investigate the Sr substitution effects on the atomic and 
local electronic structure. We also discussed the origin of the Sr substitution effects on the oxygen storage properties.

\section{Computational Methods}

We performed the first-principles electronic structure calculations based on spin-polarized DFT, using a generalized gradient approximation (GGA) with the Perdew-Burke-Ernzerhof (PBE) exchange-correlation functional[6,7], which was implemented in the plane-wave and projector augmented wave method using the Vienna Ab-initio Simulation Package (VASP 5.4.1)[8-12]. We treated the unitcells of $\mathrm{Sr}_{2} \mathrm{AlMnO}_{5}$ and $\mathrm{Sr}_{2} \mathrm{AlMnO}_{5.5}$. To reveal the $\mathrm{Sr}$ substitution effect, we also treated $\mathrm{Ca}_{2} \mathrm{AlMnO}_{5}$ and $\mathrm{Ca}_{2} \mathrm{AlMnO}_{5.5}$. We applied a $600 \mathrm{eV}$ cutoff for the plane-wave basis set without compromising computational accuracy. A $3 \times 3 \times 3$ Monkhorst-Pack special k-point grid[13] was used for the first Brillouin zone sampling with a Gaussian smearing model of $\sigma=0.05 \mathrm{eV}$ for atomic structure optimization and $\sigma=0.2 \mathrm{eV}$ for the crystal orbital Hamilton population (COHP) analysis. The on-site Coulomb interaction for Mn 3d electrons was treated based on formalisms proposed by Dudarev et al.[14]. We calculated the on-site Coulomb interaction parameter $U-J$ dependence of the enthalpy change $\Delta H$ through oxygen storage process, as shown in Fig. 2. In this paper, we adopted $U-J$ of $2.0 \mathrm{eV}$ because this value can reproduce the experimentally reported oxygen storage properties[1]. The antiferromagnetic magnetic structure was treated as previously reported.[15] Atomic positions and lattice constants were optimized until the forces on each atom were smaller than $0.02 \mathrm{eV} / \AA$.

We also calculated the $\mathrm{O}$ K-edge ELNES based on the $\mathrm{Z}+1$ approximation (e.g., replace $\mathrm{O}$ with $\mathrm{F}$ ) to model the corresponding core-hole effect. To reduce the interaction between core-hole states, we adopted $2 \times 2 \times 1$ supercells, and $2 \times 2 \times 2$ and $2 \times 2 \times 1$ Monkhorst-Pack special k-point grid were used for before and after oxygen storage, respectively.

We calculated the electron density transfer with Bader charge analysis.[16,17] We also used LOBSTER 2.2.1[18] to perform COHP analysis. We used Visualization for Electronic and Structure Analysis (VESTA) for visualizing atomic models and electron density distribution.[19] The simulated HAADF-STEM images in Fig. 1 were calculated with the Dr. Probe version 1.7 multi-slice image simulator[20], which uses the frozen phonon approximation to incorporate 
the TDS influence. In these image simulations, we used a Lorentz function with a full width at half maximum (FWHM) of $0.03 \mathrm{~nm}$ for the electron probe intensity distribution. The defocus spread was set to $3 \mathrm{~nm}$.

\section{Results and Discussions}

In Table 1, we show the calculated equilibrium lattice constants of $\mathrm{Ca}_{2} \mathrm{AlMnO}_{5+\delta}$ and $\mathrm{Sr}_{2} \mathrm{AlMnO}_{5+\delta}$. We found that the lattice expansion with $\mathrm{Sr}$ substitution because $\mathrm{Sr}^{2+}$ has a larger ionic radius of $1.21 \AA$ than $\mathrm{Ca}^{2+}(1.06 \AA)$.[21] We note that the tilting of $\mathrm{Mn}$ octahedra is suppressed by $\mathrm{Sr}$ substitution. The enthalpy changes $\Delta H$ through oxygen storage process of $\mathrm{Ca}_{2} \mathrm{AlMnO}_{5+\delta}$ and $\mathrm{Sr}_{2} \mathrm{AlMnO}_{5+\delta}$ are -1.75 and $-1.17 \mathrm{eV}$, respectively. From these results, we obtained the corresponding equilibrium temperature of oxygen storage at oxygen pressure of $2.13 \times 10^{4} \mathrm{~Pa}$, which corresponds to the oxygen partial pressure of air, are 776 and $521 \mathrm{~K}$, respectively. Therefore, Sr substitution makes the oxygen absorbed phase unstable and realizes the lower operation temperature.

To investigate the origin of the Sr substitution effects, we show the bond length between $\mathrm{O}, \mathrm{Al}$ and $\mathrm{Mn}$ atoms in Table 2. Here, $\mathrm{Al}_{t}$ and $\mathrm{Al}_{\mathrm{o}}$ indicate $\mathrm{Al}$ atoms in $\mathrm{AlO}_{4}$ tetrahedra and $\mathrm{AlO}_{6}$ octahedra, respectively. The indices of $\mathrm{O}$ atoms show the atoms where $\mathrm{O}$ atoms connect. As we mentioned, there are five non-equivalent $\mathrm{O}$ sites in these systems, i.e., $\mathrm{Mn}-\mathrm{Mn}, \mathrm{Mn}-\mathrm{Al}_{\mathrm{t}}, \mathrm{Mn}-\mathrm{Al}_{\mathrm{o}}, \mathrm{Al}_{\mathrm{t}}-\mathrm{Al}_{\mathrm{t}}$ and $\mathrm{Al}_{\mathrm{o}}-\mathrm{Al}_{\mathrm{o}}$. In the case of $\mathrm{Ca}_{2} \mathrm{AlMnO}_{5.5}$, the bond length between $\mathrm{Mn}$ and $\mathrm{O}_{\mathrm{Mn}-\mathrm{Alt}}$ atoms is $2.165 \AA$, which is shorter than that of $\mathrm{Ca}_{2} \mathrm{AlMnO}_{5}(2.308 \AA)$. This can be explained by the disappearance of the Jahn-Teller distortion.[5] From Bader charge analysis, we can see that the Mn oxidation states in $\mathrm{Ca}_{2} \mathrm{AlMnO}_{5}$ and $\mathrm{Ca}_{2} \mathrm{AlMnO}_{5.5}$ are +3 and +4 , respectively. Owing to this change of the Mn oxidation states, the Jahn-Teller distortion of Mn octahedra is released.

On the other hand, in the case of $\mathrm{Sr}_{2} \mathrm{AlMnO}_{5.5}$, the bond length between $\mathrm{Mn}$ and $\mathrm{O}_{\mathrm{Mn}-\mathrm{Alt}}$ atoms is $2.412 \AA$, which almost corresponds to that of $\mathrm{Sr}_{2} \mathrm{AlMnO}_{5}(2.441 \AA)$. This is because the large ionic radius of $\mathrm{Sr}^{2+}$ prevents the disappearance of the Jahn-Teller distortion. This long bond length between Mn and $\mathrm{O}_{\mathrm{Mn}-\mathrm{Alt}}$ atoms may suppress the formation of the covalent bond between these atoms.

In Fig. 3, the electron density distribution in the vicinity of Mn octahedra in $\mathrm{Ca}_{2} \mathrm{AlMnO}_{5.5}$ and $\mathrm{Sr}_{2} \mathrm{AlMnO}_{5.5}$. The electron density between $\mathrm{Mn}$ and $\mathrm{O}_{\mathrm{Mn} \text {-Alt }}$ atoms in $\mathrm{Sr}_{2} \mathrm{AlMnO}_{5.5}$ is lower than that in $\mathrm{Ca}_{2} \mathrm{AlMnO}_{5.5}$. This result indicates the smaller 
hybridization of the electronic orbitals of $\mathrm{Mn}$ and $\mathrm{O}_{\mathrm{Mn} \text {-Alt }}$ atoms. To investigate the local electronic structure more detail, we performed COHP analysis. The results of COHP analysis of before and after oxygen storage in Fig. 4 and 5, respectively. We plotted the sum of -COHP of up and down spin electrons in Fig. 4 and 5, therefore, the positive and negative values indicate the bonding and antibonding orbitals. We note that the hybridized electronic orbitals mainly exist from -5 to $5 \mathrm{eV}$. In the both cases of $\mathrm{Ca}_{2} \mathrm{AlMnO}_{5+\delta}$ and $\mathrm{Sr}_{2} \mathrm{AlMnO}_{5+\delta}$, the antibonding orbitals exist around $-1 \mathrm{eV}$ in $\mathrm{Mn}-\mathrm{O}_{\mathrm{Mn}-\mathrm{Mn}}$ and $\mathrm{Mn}-\mathrm{O}_{\mathrm{Mn}-\mathrm{Alt}}$ before oxygen storage, and move above the Fermi level after oxygen storage. These results indicates that the Mn oxygen states change from +3 and +4 through oxygen storage in $\mathrm{Ca}_{2} \mathrm{AlMnO}_{5+\delta}$ and $\mathrm{Sr}_{2} \mathrm{AlMnO}_{5+\delta}$. In the both cases of $\mathrm{Ca}_{2} \mathrm{AlMnO}_{5+\delta}$ and $\mathrm{Sr}_{2} \mathrm{AlMnO}_{5+\delta}$, we can find the large peaks, which means the strong electronic orbital hybridization, between $\mathrm{Mn}$ and $\mathrm{O}_{\mathrm{Mn}-\mathrm{Mn}}$ atoms. Next, we focused on $\mathrm{Mn}-\mathrm{O}_{\mathrm{Mn}-\mathrm{Alt}}$. The peak intensity of $\mathrm{Mn}-\mathrm{O}_{\mathrm{Mn} \text {-Alt }}$ is smaller than that of $\mathrm{Mn}-\mathrm{O}_{\mathrm{Mn}-\mathrm{Mn}}$, which indicates the weak electronic orbital hybridization because of their long bond length. The peak intensity of $\mathrm{Mn}-\mathrm{O}_{\mathrm{Mn} \text {-Alt }}$ in $\mathrm{Sr}_{2} \mathrm{AlMnO}_{5.5}$ is smaller than that of $\mathrm{Ca}_{2} \mathrm{AlMnO}_{5.5}$, while the Sr substitution does not affect the peak intensity of Mn-OMn-Alt before oxygen storage. This is because the $\mathrm{Sr}$ substitution lengthens the bond length between $\mathrm{Mn}$ and $\mathrm{O}_{\mathrm{Mn}-\mathrm{Alt}}$ atoms in $11 \%$ after oxygen storage, as shown in Table 2. Even though we can find the slight energy shifts, the peak intensity of - $\mathrm{COHP}$ does not change with $\mathrm{Sr}$ substitution in all - COHP results except $\mathrm{Mn}-\mathrm{O}_{\mathrm{Mn}-\mathrm{Alt}}$ after oxygen storage. Therefore, we can conclude the origin of the low oxygen capability of $\mathrm{Sr}_{2} \mathrm{AlMnO}_{5.5}$ is the weak covalent bond between $\mathrm{Mn}$ and $\mathrm{O}_{\mathrm{Mn}-\mathrm{Alt}}$ atoms.

Finally, we discuss the Sr substitution effects on the EELS experiment. Figure 6 shows the calculated $\mathrm{O}-\mathrm{K}$ edge ELNES using $\mathrm{Z}+1$ approximation. The $\mathrm{O}-\mathrm{K}$ edge ELNES is the electron excitation from occupied 1s to unoccupied $2 \mathrm{p}$ orbitals of $\mathrm{O}$ atoms. Therefore, O-K edge ELNES spectra reflect the DOS of unoccupied $2 p$ orbitals of $\mathrm{O}$ atoms. We note that hybridization which we considered in this paper consists of $\mathrm{Mn} d$ and $\mathrm{O} p$ orbitals, and the unoccupied hybridized orbitals near the Fermi level are the origins of the prepeak $(\sim 3 \mathrm{eV})$ and main peak $(4 \mathrm{eV} \sim)$ of O-K edge ELNES.[5] As we mentioned, the hybridization of $\mathrm{Mn}-\mathrm{O}_{\mathrm{Mn}-\mathrm{Alt}}$ in $\mathrm{Sr}_{2} \mathrm{AlMnO}_{5.5}$ is weaker than that in $\mathrm{Ca}_{2} \mathrm{AlMnO}_{5.5}$. Therefore, the relative intensity of the prepeak to the main peak of O-K edge ELNES, especially at $\mathrm{O}_{\mathrm{Mn} \text {-Alt }}$ sites, also becomes weaker with Sr substitution, which can be seen below $3 \mathrm{eV}$ in Fig. 6 (b). We also note that the main peak intensity 
near the onset of O-K edge ELNES before oxygen storage becomes weaker with $\mathrm{Sr}$ substitution, which can be clearly seen around $4 \mathrm{eV}$ in Fig. 6 (a). These trends indicate the possibility of the finding the Sr segregated regions from O-K edge ELNES spectra in addition to the atomic structure analysis and Z-contrast from the HAADF-STEM imaging.

\section{Conclusion}

In this paper, we performed the first-principles electronic structure calculations based on spin-polarized DFT to investigate the Sr substitution effects on the atomic and local electronic structure of $\mathrm{Ca}_{2} \mathrm{AlMnO}_{5+\delta}$. Because of the ionic radius difference between $\mathrm{Sr}^{2+}$ and $\mathrm{Ca}^{2+}$, the lattice expansion occurs with $\mathrm{Sr}$ substitution. Especially, $\mathrm{Sr}$ substitution lengthen the bond length between $\mathrm{Mn}$ and $\mathrm{O}_{\mathrm{Mn} \text {-Alt }}$ atoms after oxygen storage, because the large $\mathrm{Sr}^{2+}$ prevents the release of the Jahn-Teller distortion. From the point of oxygen storage properties, Sr substitution makes the oxygen absorbed phase unstable and realizes the lower operation temperature. From the local electronic structure analysis, we found that the covalent bonding between $\mathrm{Mn}$ and $\mathrm{O}_{\mathrm{Mn} \text {-Alt }}$ atoms weaken with Sr substitution, which results in the unstable oxygen absorbed phase and weak prepeak and main peak intensity near the onset of O-K edge ELNES of $\mathrm{O}_{\mathrm{Mn} \text {-Alt }}$ atoms.

\section{Acknowledgements}

This work was carried out using the facilities of the Supercomputer Center, Institute for Solid State Physics, University of Tokyo, Japan.

\section{Reference}

[1] T. Motohashi, Y. Hirano, Y. Masubuchi, K. Oshima, T. Setoyama, S. Kikkawa, Chem. Mater. 25, 372 (2013).

[2] C. Ling. R. Zhang, H. Jia, ACS Appl. Mater. Interfaces 7, 14518 (2015).

[3] T. Nomura, C. Zhu, N. Sheng, R. Murai, T. Akiyama, J. Alloy. Compd. 646, 900 (2015).

[4] C. Ling, R. Zhang, H. Jia, ACS Appl. Mater. Interfaces 7, 14518 (2015).

[5] G. Saito, Y. Kunisada, K. Hayami, T. Nomura, N. Sakaguchi, Chem. Mater. 29, 648 (2017). 
[6] J.P. Perdew, K. Burke, M. Ernzerhof, Phys. Rev. Lett. 77, 3865 (1996).

[7] J.P. Perdew, K. Burke, M. Ernzerhof, Phys. Rev. Lett. 78, 1396 (1997).

[8] G. Kresse, J. Hafner, Phys. Rev. B 47, 558 (1993).

[9] G. Kresse, J. Hafner, Phys. Rev. B 49, 14251 (1994).

[10] P.E. Blöchl, Phys. Rev. B 50, 17953 (1994).

[11] G. Kresse, J. Furthmüller, Phys. Rev. B 54, 11169 (1996).

[12] G. Kresse, D. Joubert, Phys. Rev. B 59, 1758 (1999).

[13] H.J. Monkhorst, J.D. Pack, Phys. Rev. B 13, 5188 (1976).

[14] S.L. Dudarev, G.A. Botton, S.Y. Savrasov, C.J. Humphreys, A.P. Sutton, Phys. Rev. B 57, 1505 (1998).

[15] H.M. Palmer, A. Snedden, A.J. Wright, C. Greaves, Chem. Mater. 18, 1130 (2006).

[16] R.F.W. Bader, Atoms in Molecules: A Quantum Theory, Oxford University Press, New York, U.S.A., 1990.

[17] W. Tang, E. Sanville, G. Henkelman, J. Phys.: Condens. Matter 21, 084204 (2009).

[18] S. Maintz, V. L. Deringer, A. L. Tchougréeff, R. Dronskowski, J. Comput.

Chem. 37, 1030 (2016).

[19] K. Momma, F. Izumi, J. Appl. Crystallogr. 44, 1272 (2011).

[20] J. Barthel, Dr. Probe-STEM Simulation Software, http://www.er-c.org/barthel/drprobe/.

[21] R. D. Shannon, Acta Cryst. A32, 751 (1976). 
Table 1 the calculated equilibrium lattice constants $(\AA)$ of $\mathrm{Ca}_{2} \mathrm{AlMnO}_{5+\delta}$ and $\mathrm{Sr}_{2} \mathrm{AlMnO}_{5+\delta}$.

\begin{tabular}{ccccc}
\hline & \multicolumn{2}{c}{$\mathrm{Ca}_{2} \mathrm{AlMnO}_{5+\delta}$} & \multicolumn{2}{c}{$\mathrm{Sr}_{2} \mathrm{AlMnO}_{5+\delta}$} \\
\cline { 2 - 5 } & $\delta=0$ & $\delta=0.5$ & $\delta=0$ & $\delta=0.5$ \\
\hline$a$ & 5.276 & 5.302 & 5.391 & 5.399 \\
$b$ & 15.164 & 29.534 & 16.058 & 31.339 \\
$c$ & 5.523 & 5.430 & 5.599 & 5.471 \\
\hline
\end{tabular}


Table 2 The calculated bond length between $\mathrm{O}, \mathrm{Al}$ and $\mathrm{Mn}$ atoms in $\mathrm{Ca}_{2} \mathrm{AlMnO}_{5+\delta}$ and $\mathrm{Sr}_{2} \mathrm{AlMnO}_{5+\delta}$.

\begin{tabular}{lcccc}
\hline & \multicolumn{2}{c}{$\mathrm{Ca}_{2} \mathrm{AlMnO}_{5+\delta}$} & \multicolumn{2}{c}{$\mathrm{Sr}_{2} \mathrm{AlMnO}_{5+\delta}$} \\
\cline { 2 - 5 } & $\delta=0$ & 1.927 & 1.943 & $\delta=0.5$ \\
\hline $\mathrm{Mn}-\mathrm{O}_{\mathrm{Mn}-\mathrm{Mn}}$ & 1.910 & 2.165 & 2.441 & 1.925 \\
$\mathrm{Mn}-\mathrm{O}_{\text {Mn-Alt }}$ & 2.308 & 1.804 & - & 2.412 \\
$\mathrm{Mn}-\mathrm{O}_{\text {Mn-Alo }}$ & - & 1.804 & 1.796 & 1.809 \\
$\mathrm{Al}_{\mathrm{t}}-\mathrm{O}_{\text {Alt-Alt }}$ & 1.819 & 1.765 & 1.770 & 1.787 \\
$\mathrm{Al}_{\mathrm{t}}-\mathrm{O}_{\text {Mn-Alt }}$ & 1.755 & 1.904 & - & 1.783 \\
$\mathrm{Al}_{\mathrm{o}}-\mathrm{O}_{\text {Alo-Alo }}$ & - & 1.982 & - & 1.918 \\
$\mathrm{Al}_{\mathrm{o}}-\mathrm{O}_{\text {Mn-Alo }}$ & - & & & 2.021 \\
\hline
\end{tabular}




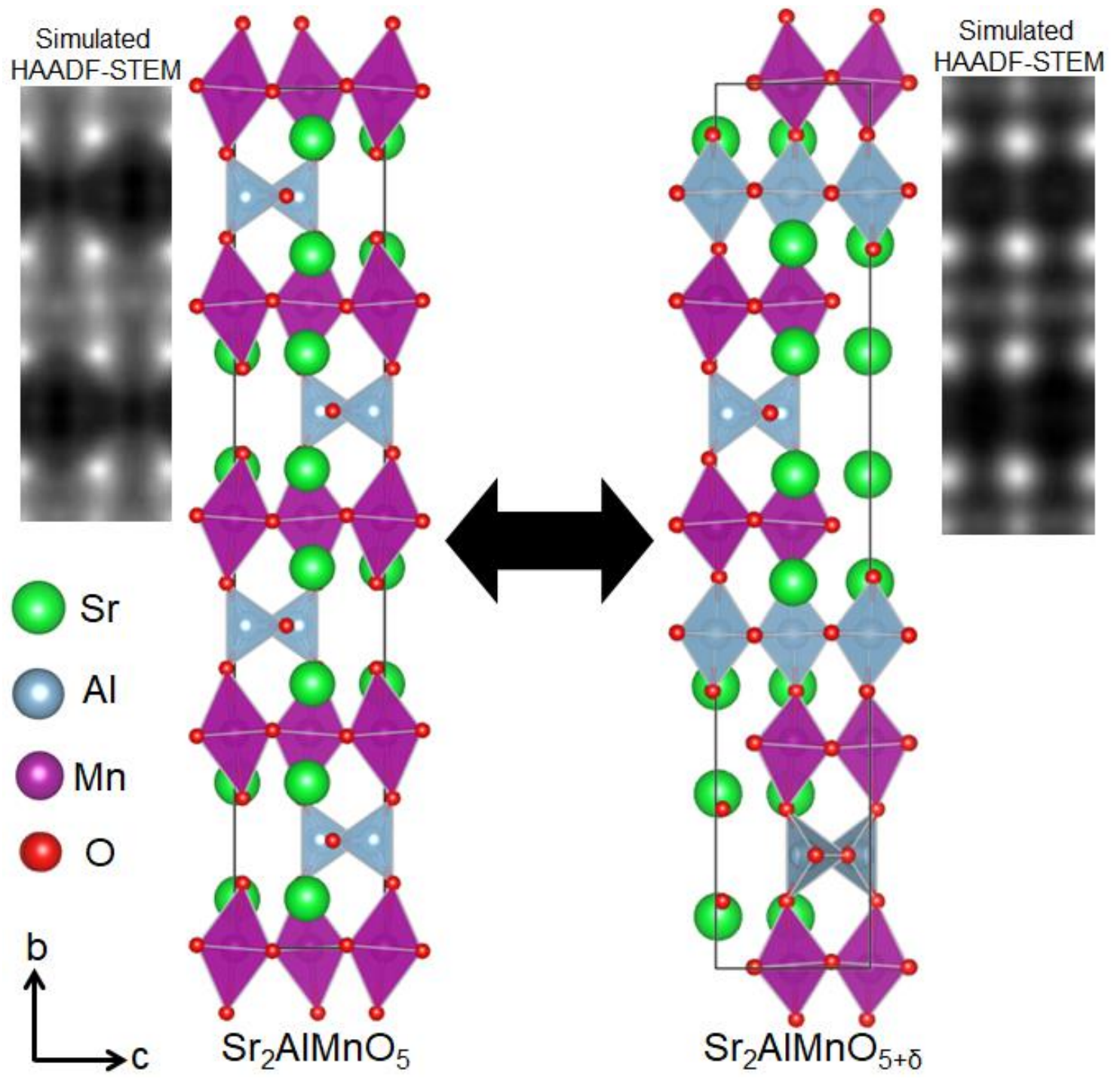

Figure 1 (Color online) Atomic structure models and corresponding simulated HAADF-STEM images of brownmillerite-type $\mathrm{Sr}_{2} \mathrm{AlMnO}_{5}$ and $\mathrm{Ca}_{2} \mathrm{AlMnO}_{5.5}$. 


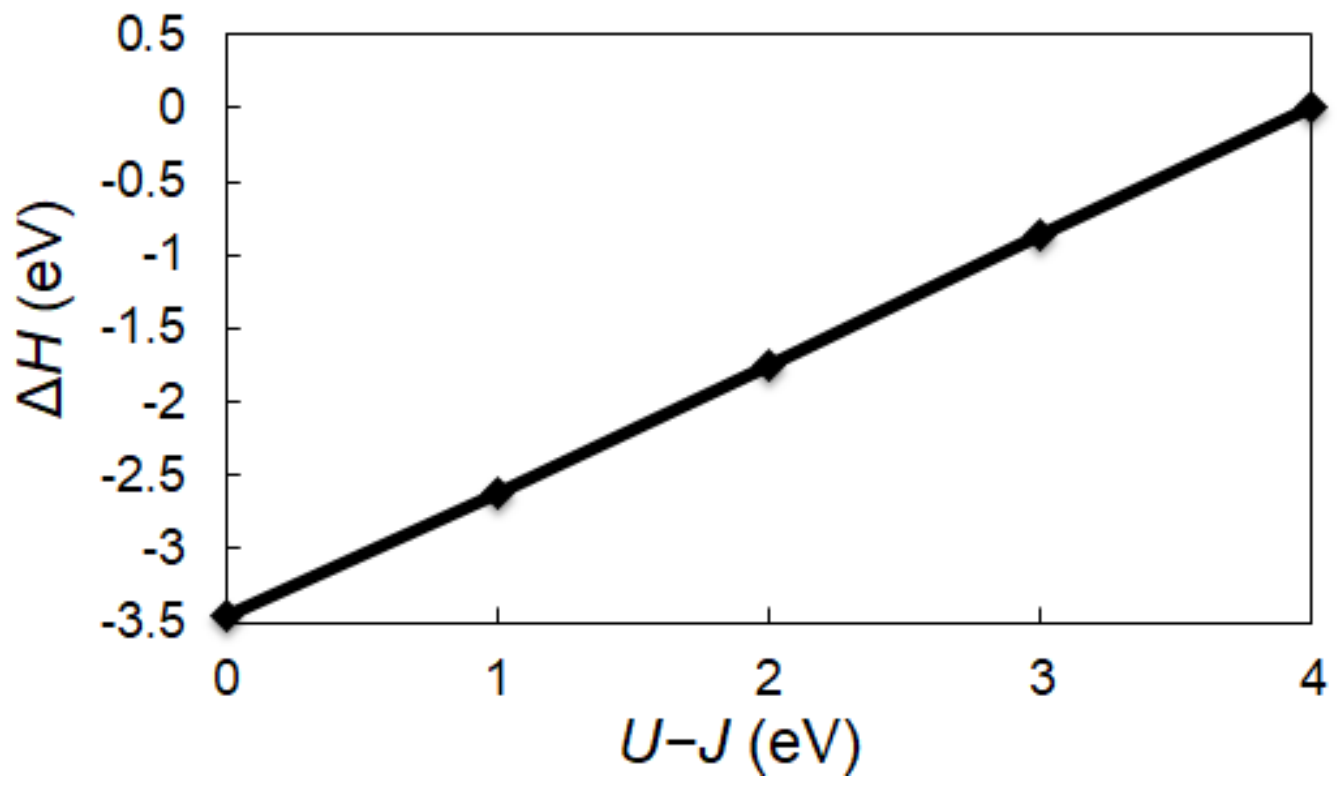

Figure $2 U-J$ dependence of the enthalpy change $\Delta H$ through oxygen storage process. 
(a)

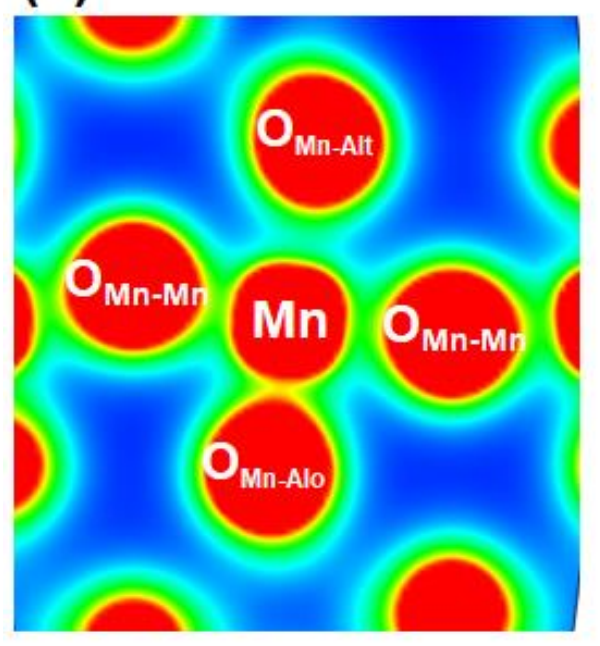

(b)

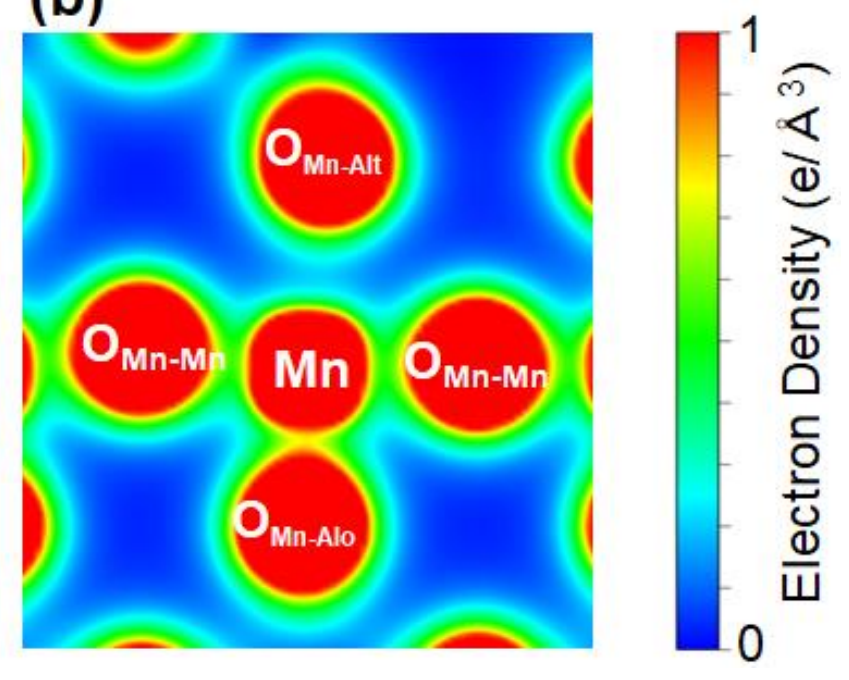

Figure 3 (Color online) The electron density distribution in the vicinity of Mn octahedra in (a) $\mathrm{Ca}_{2} \mathrm{AlMnO}_{5.5}$ and (b) $\mathrm{Sr}_{2} \mathrm{AlMnO}_{5.5}$. 


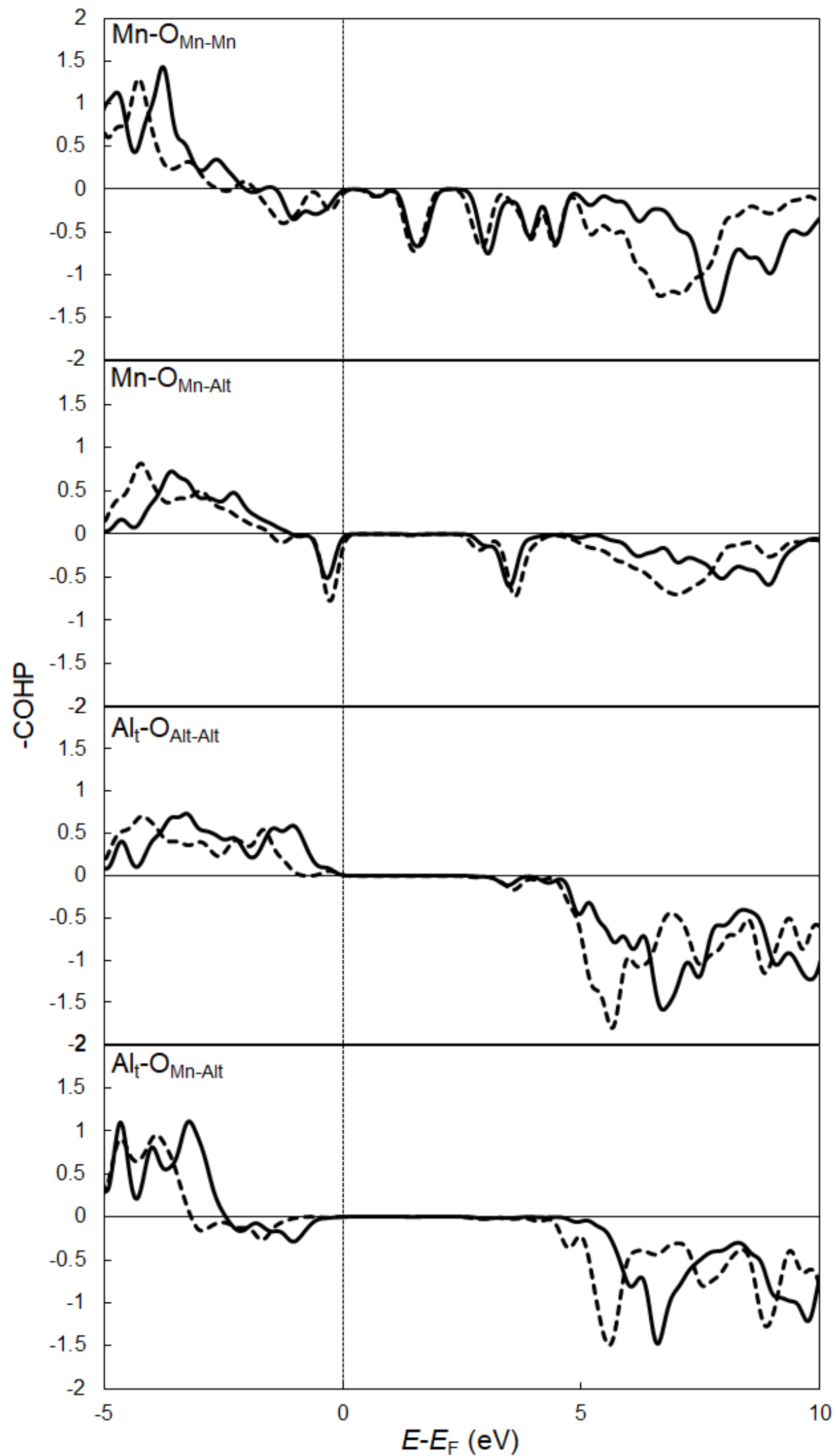

Figure 4 The crystal orbital Hamilton population of $\mathrm{Sr}_{2} \mathrm{AlMnO}_{5}$ and $\mathrm{Ca}_{2} \mathrm{AlMnO}_{5}$. The solid and dashed lines are $\mathrm{Sr}_{2} \mathrm{AlMnO}_{5}$ and $\mathrm{Ca}_{2} \mathrm{AlMnO}_{5}$, respectively. 


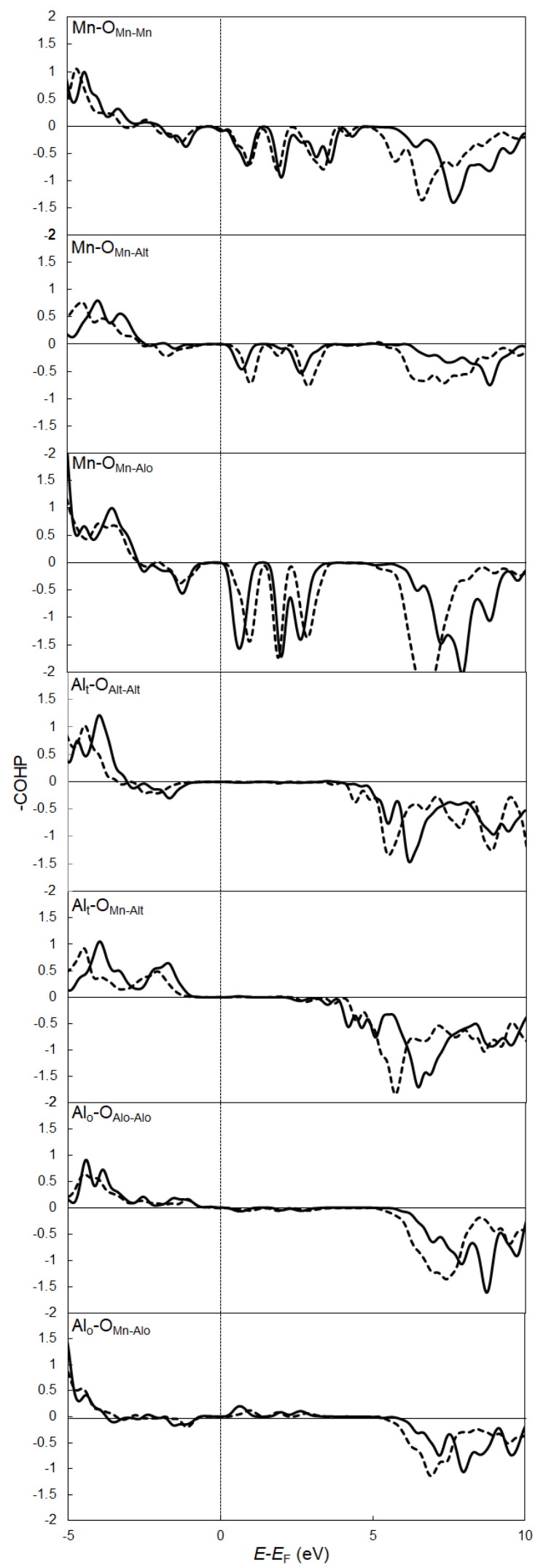

Figure 5 The crystal orbital Hamilton population of $\mathrm{Sr}_{2} \mathrm{AlMnO}_{5.5}$ and $\mathrm{Ca}_{2} \mathrm{AlMnO}_{5.5}$. The solid and dashed lines are $\mathrm{Sr}_{2} \mathrm{AlMnO}_{5.5}$ and $\mathrm{Ca}_{2} \mathrm{AlMnO}_{5.5}$, respectively. 

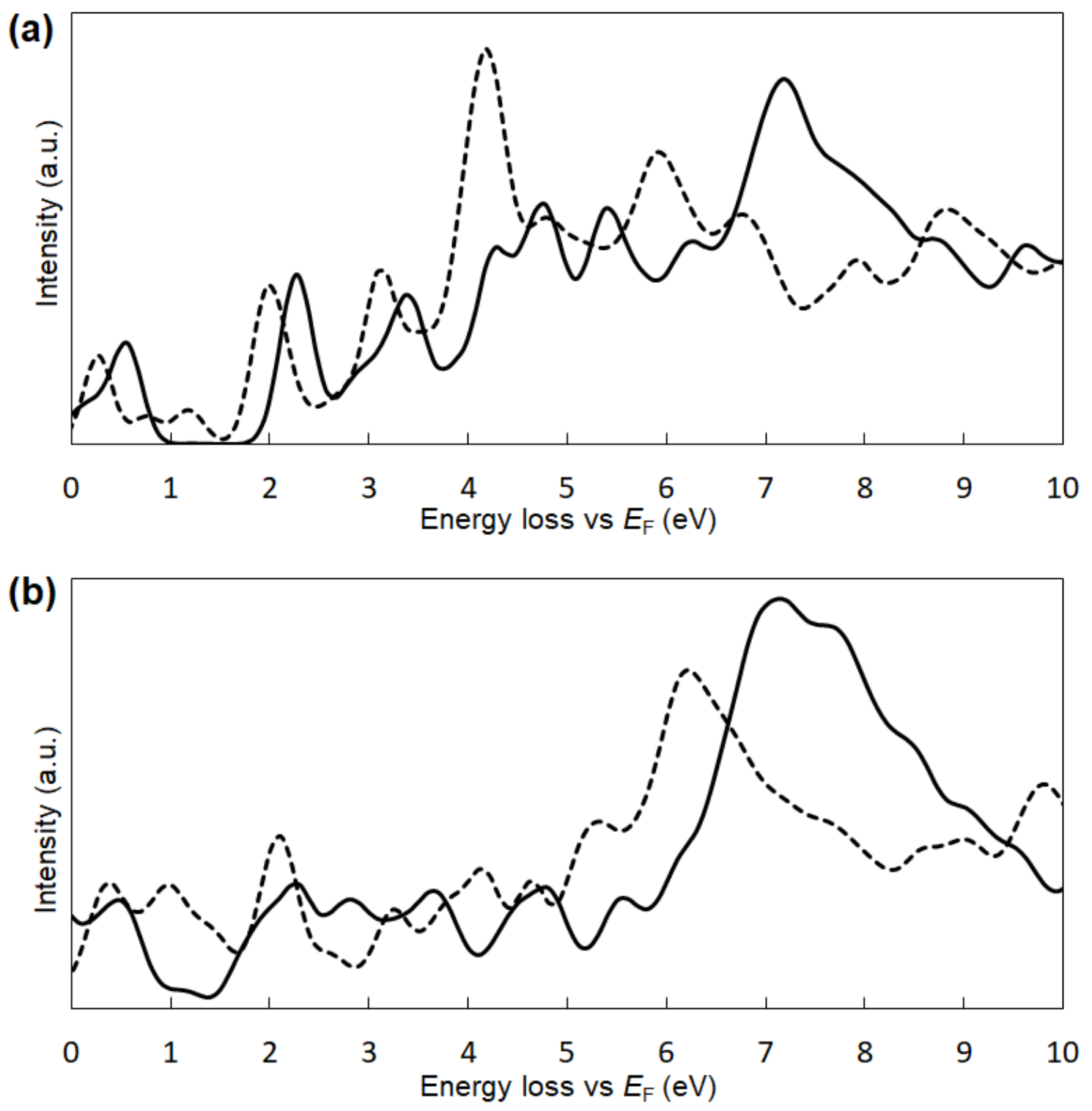

Figure 6 The calculated O-K edge ELNES of (a) before and (a) after oxygen storage. The solid and dashed lines are $\mathrm{Sr}_{2} \mathrm{AlMnO}_{5 .+\delta}$ and $\mathrm{Ca}_{2} \mathrm{AlMnO}_{5+\delta}$, respectively. 